aneuploidy with increasing age of the female partner: a review of 15,169 consecutive trophectoderm biopsies evaluated with comprehensive chromosomal screening. Fertil Steril (2014) 101:656-63.

4. Nayar K. D., Gahlot R., Kant G., Singh M., Sharma $\mathbf{N}$. Is time lapse a better option to improve clinical outcome over standard incubatora case controlled study. ASRM 2018.

5. Nelson SM, Lawlor DA. Predicting live birth, preterm delivery, and low birth weight in infants born from in vitro fertilisation: a prospective study of 144,018 treatment cycles. PLoS Med (2011) 8.

\title{
TÌNH TRANG SÂU RĂNG VÀ NHU CẦU ĐIỀU TRI Ở TRẺ 5, 12 TUỔI DÂN TộC THÁI Ở HUYỆN CON CUÔNG, TỈNH NGHỆ AN NĂM 2015
}

\author{
Vi Việt Cường ${ }^{1}$, Phạm Quốc Hùng ${ }^{2}$
}

\section{TÓM TẮT}

Nghiên cứu mô tả cắt ngang nhằm đánh giá tình trạng sâu răng ở trẻ 5, 12 tuổi dân tộc Thái tại huyện Con Cuông, tỉnh Nghê An. Nghiên cứu được hoàn thành vào tháng $5 / 2015$ với 473 trẻ 5 tuổi tại 9 trường mâm non và 476 trẻ 12 tuổi tai 9 trường trung hoc cơ sở ở huyện. Nghiên cứu theo phương pháp điều tra và phân loại của Tổ chức Y tế Thế giới (WHO) năm 2013; Kết quả nghiên cứu cho thấy: trẻ 5 tuổi: tỷ lệ sâu răng ở mức trung bình $(59,8 \%)$; nam $(62 \%)$ cao hơn nữ $(57,2 \%)$ với sự khác biệt không có ý nghĩa thống kê ( $p>0,05)$; Sâu-mất-trám răng ở mức độ trung bình $(2,71 \pm 3,22)$, trong đó chủ yếu là chỉ số sâu, chỉ số mất không có, chỉ số trám rất ít; Sâu-mất-trám mă̆t răng trung bình khá cao $(8,36 \pm 11,5)$; Nhu cầu điều trị: 0,52 răng/ 1 trẻ cân trám 1 mặt răng, 0,79 răng/ 1 trẻ cần trám 2 mă̆t răng. Trẻ 12 tuổi: tỷ lê sâu răng ở mức độ thấp $(14,3 \%)$; nam $(11,6 \%)$ thẩp hơn nữ $(16,9 \%)$ với sự khác biêt không có ý nghĩa thống kê $(p>0,05)$. Sâu-mất-trám răng ở mức độ rất thấp $(0,21 \pm 0,56)$ và Sâu-mất-trám măt răng ở mức rất thấp $(0,45 \pm 1,56)$. Nhu câu điều trị: 0,13 răng/1 trẻ cần trám 1 mặt răng; 0,04 răng/1 trẻ cần trám 2 mặt răng.

Ti̛ khóa: sâu răng, nhu cầu điều trị, trẻ năm tuổi, trẻ 12 tuổi

\section{SUMMARY}

\section{SITUATION OF TOOTH DECAY AND}

TREATMENT NEEDS IN THAI CHILDREN

AGED 5 AND 12 YEAR-OLD, IN CON CUONG DISTRICT, NGHE AN PROVINCE IN 2015

A cross-sectional descriptive study was implemented to assess tooth decay and treatment needs among children aged 5 and 12 year-old of Thai ethnic group in Con Cuong district, Nghe An province. The study was completed in May 2015 with 473 children aged 5-year-old in 9 preschools and 476 children aged 12-year-old in 9 middle schools in the

\footnotetext{
${ }^{1}$ Đại học Quốc tế Hồng Bàng,

${ }^{2}$ Trường Đại học Y Hà Nội

Chịu trách nhiệm chính: Vi Việt Cường

Email: vivietcuongdr05@gmail.com

Ngày nhận bài: 18.10.2021

Ngày phản biện khoa học: 16.12.2021

Ngày duyệt bài: 24.12.2021
}

district, according to the method of investigation and classification of WHO-2013; Research results showed that: 5-year-old children: the rate of tooth decay was average $(59.8 \%)$; male $(62 \%)$ higher than female $(57.2 \%)$ with the difference not statistically significant ( $p>0.05$ ); the average of tooth decay-loss-filling was at an middle level $(2.71 \pm 3.22)$, in which the index of decay was mainly, the index of loss was absent, the index of filling was very little; the average of decayloss-filling of tooth face was quite high $(8.36 \pm 11.5)$; treatment needs: 0.52 teeth/ 1 child need filling 1 tooth, and 0.79 teeth/ 1 child need filling 2 teeth. 12year-old children: the rate of tooth decay was low $(14.3 \%)$; male $(11.6 \%)$ lower than female $(16.9 \%)$ with the difference not statistically significant ( $p>0.05)$; the average of tooth decay-loss-filling was very low $(0.21 \pm 0.56)$, and the average of decay-lossfilling of tooth face was very low $(0.45 \pm 1.56)$; treatment needs: 0.13 teeth/ 1 child need filling 1 tooth, and 0.04 teeth 1 child need filling 2 teeth.

Keywords: tooth decay, treatment needs, fiveyear-old children, 12-year-old children

\section{I. ĐẶT VẤN ĐỀ}

Tình trạng sâu răng của trẻ em Việt Nam vẫn đang là vấn đề sức khỏe công cộng cần quan tâm, đặc biệt là vùng sâu vùng xa, đồng bào dân tộc thiểu số nơi gặp nhiều khó khăn trong chương trình chăm sóc sức khỏe răng miệng định hướng đến năm 2030 của Chính phủ [1]. Để có thêm dữ liệu làm cơ sở cho thiết kễ các chương trình can thiệp phòng chống sâu răng phù hợp cho từng khu vực và từng lứa tuổi khác nhau cần có thêm những nghiên cứu ở những nhóm dân cư đắc biêt là đồng bào các dân tộc thiểu số vùng sâu vùng xa. Nghiên cứu này được tiến hành nhằm đánh giá tình trạng sâu răng và nhu cầu điều trị của trẻ dân tộc Thái 5 tuổi tại các trường mầm non và trẻ dân tộc Thái 12 tuổi tại các trường trung học cơ sở thuộc 9 xã của huyện Con Cuông, tỉnh Nghệ An.

II. ĐỐI TƯỢNG VÀ PHƯƠNG PHÁP NGHIÊN CỨU

Đối tượng nghiên cứu: toàn bộ trẻ dân tộc Thái 5 tuổi ở 9 trường mầm non và 12 tuổi ở 9 
trường trung học cơ sở được chọn ngẫu nhiên thuộc huyện Con Cuông, tỉnh Nghệ An có cha mẹ hoặc người nuôi dưỡng đồng ý cho tham gia nghiên cứu.

Thiết kế nghiên cứu: Nghiên cứu mô tả cắt ngang.

Thời gian: từ tháng 10/2014 đến 5/2015.

Cỡ mẫu, chọn mẫu: 473 trẻ 5 tuổi tại 9 trường mầm non và 476 trẻ 12 tuổi tại 9 trường trung học cơ sở đã tham gia nghiên cứu.

Phương pháp đánh giá: Sử dụng bộ đồ khám răng miệng và Phiếu khám ghi nhận tình trạng sâu răng và phân loại theo hướng dẫn của WHO 2013 [2].

Phân tích và xử lý số liệu: Số liệu được nhập bằng phần mềm MS. Excel 2016 và phẩn tích bằng phần mềm SPSS 16.0.

Đạo đức nghiên cứu: Đề cương nghiên cứu đã được Hội đồng Khoa học Đại học Y Dược Tp Hồ Chí Minh phê duyệt. Triển khai tuân thủ đạo đức nghiên cứu y sinh.

\section{KẾT QUẢ NGHIÊN CỨU}

Tổng số trẻ 5 tuổi dân tộc Thái tham gia nghiên cứu là 473 em, trong đó số trẻ nam là 258 em, chiếm tỷ lệ 54,5\%; số trẻ nữ 215 em, chiếm tỷ lệ 45,5\%. Tổng số trẻ 12 tuổi tham gia nghiên cứu là 476 em, số trẻ nam là 233 em, chiếm tỷ lệ $49 \%$; số trẻ nữ là 243 em, chiếm tỳ lệ $51 \%$.

\section{Tình trạng bệnh sâu răng}

Bảng 1. Tỷ lệ \% sâu răng và không sâu răng theo tuổi và giới

\begin{tabular}{|c|c|c|c|c|c|c|c|c|}
\hline \multirow{2}{*}{ Nhóm } & \multirow{2}{*}{ Đặc điểm } & \multicolumn{2}{|c|}{ Nam } & \multicolumn{2}{|c|}{ Nữ } & \multicolumn{2}{|c|}{ Tống } & \multirow{2}{*}{$\mathbf{p}^{*}$} \\
\hline & & n & $\%$ & $\mathbf{n}$ & $\%$ & $\mathbf{n}$ & $\%$ & \\
\hline \multirow{2}{*}{5 tuổi } & Sâu răng & 160 & 62,0 & 123 & 57,2 & 283 & 59,8 & \multirow[b]{2}{*}{0,29} \\
\hline & Không sâu răng & 98 & 38,0 & 92 & 42,8 & 190 & 40,2 & \\
\hline \multirow{2}{*}{$\begin{array}{c}12 \\
\text { tuổi }\end{array}$} & Sâu răng & 27 & 11,6 & 41 & 16,9 & 68 & 14,3 & \multirow{2}{*}{0,10} \\
\hline & Không sâu răng & 206 & 88,4 & 202 & 83,1 & 408 & 85,7 & \\
\hline
\end{tabular}

*) Kiểm định Chi bình phương

Bảng 1 cho thấy: Tỷ lệ sâu răng của trẻ 5 tuổi là 59,8 \%; sự khác biệt tỷ lệ sâu răng giữa trẻ nam $(62 \%)$ và trẻ nữ $(57 \%)$ không có ý nghĩa thống kê $(p>0,05)$. Tỷ lệ sâu răng của trẻ 12 tuổi là 14,3 \%. Tỷ lệ sâu răng của trẻ nam $(11,6 \%)$ thấp hơn trẻ nữ $(16,9 \%)$, tuy nhiên sự khác biệt không có ý nghĩa thống kê $(p>0,05)$.

Tỷ lệ trẻ có răng mất và răng trám

Bảng 2. Số lượng trẻ và tỷ lệ \% có răng mất và răng trám

\begin{tabular}{|c|c|c|c|c|c|c|c|}
\hline \multirow{2}{*}{\multicolumn{2}{|c|}{ Nhóm }} & \multicolumn{3}{|c|}{ Răng mất } & \multicolumn{3}{|c|}{ Răng trám } \\
\hline & & $\mathbf{n}$ & $\%$ & p & $\mathbf{n}$ & $\%$ & $\mathbf{p}^{*}$ \\
\hline \multirow{3}{*}{5 tuổi } & Nam & 0 & 0 & & 2 & 0,8 & \multirow{3}{*}{0,855} \\
\hline & Nữ & 0 & 0 & & 2 & 0,9 & \\
\hline & Tống & 0 & 0 & & 4 & 1,7 & \\
\hline \multirow{3}{*}{12 tuổi } & Nam & 0 & 0 & & 3 & 1,3 & \multirow{3}{*}{0,680} \\
\hline & Nữ & 0 & 0 & & 2 & 0,8 & \\
\hline & Tống & 0 & $\mathbf{0}$ & & 5 & 2,1 & \\
\hline
\end{tabular}

*)Kiếm định chính xác Fisher

Kêt quả nghiên cứu Bảng 2 cho thấy: Không có tỷ lệ răng mất ở cả 2 lứa tuổi, trong khi đó tỷ lệ răng trám cũng rất thấp với $2,1 \%$ ở trẻ 12 tuổi và $1,7 \%$ ở trẻ 5 tuổi.

Sâu mất trám răng và sâu mất trám mặt răng

Bảng 3: Sâu-mất-trám răng và sâu-mẩt-trám măt răng

\begin{tabular}{|c|c|c|c|c|c|}
\hline & Sâu & Mất & Trám & SMT-R & SMT-MR \\
\hline Nhóm & $\mathrm{TB} \pm$ ĐLC & $\mathrm{TB} \pm$ ĐLC & $\mathrm{TB} \pm$ ĐLC & $\mathrm{TB} \pm$ ĐLC & $\mathrm{TB} \pm$ ĐLC \\
\hline 5 tuối & $2,70 \pm 3,21$ & $0 \pm 0$ & $0,01 \pm 0,12$ & $2,71 \pm 3,22$ & $8,36 \pm 11,5$ \\
\hline 12 tuối & $0,19 \pm 0,53$ & $0 \pm 0$ & $0,01 \pm 0,15$ & $0,21 \pm 0,56$ & $0,45 \pm 1,56$ \\
\hline
\end{tabular}

Kết quả nghiên cứu bảng 3 cho thấy: Sâu-mất-trám răng (SMT-R) của trẻ 5 tuối là 2,71; xếp vào mức độ trung bình theo phân loại của WHO 2013. Của trẻ 12 tuổi là 0,21 xếp vào mức độ rất thấp. Trong 3 thành phần của SMT-R thành phần sâu chiếm tỷ lệ cao nhất, trong khi đó thành phần trám rất thấp, thành phần mất không có. Sâu-mất-trám mặt răng (SMT-MR) của trẻ 5 tuổi là 8,36 trong khi đó của trẻ 12 tuổi là 0,45 .

Nhu câu điều trị bệnh sâu răng

Bảng 4: Trung binh số răng sấu cần điều trị/1 trẻ 


\begin{tabular}{|c|c|c|c|c|}
\hline Nhóm & Trám 1 mặt răng & Trám 2 mặt răng & Điêuu trị tủy & Nhố răng \\
\hline 5 tuối & 0,52 & 0,79 & 0,66 & 0,26 \\
\hline 12 tuối & 0,13 & 0,04 & 0,01 & 0,02 \\
\hline
\end{tabular}

Kết quả nghiên cứu bảng 4 cho thấy: Trung bình số răng cần điều trị ở trẻ 5 tuối là: trám 1 mặt răng: 0,52 răng/trẻ; trám $\geq 2$ mặt răng: 0,79 răng/trẻ; Điều trị tủy: 0,66 răng/trẻ; Nhổ răng: 0,26 răng/trẻ. Trung bình số răng cần điều trị ở trẻ 12 tuổi là: trám 1 mặt răng: 0,13 răng/trẻ; trám $\geq$ 2mặt răng: 0,04/trẻ; điêuu trị tủy: 0,01 răng/trẻ: nhổ răng: 0,02 răng/trẻ.

\section{BÀN LUẬN}

Số trẻ tham gia nghiên cứu gồm 473 trẻ 5 tuổi và 476 trẻ 12 tuổi đủ đáp ứng cõ̃ mẫu thiết kế với số trẻ dân tộc Thái 5 tuổi và 12 tuổi trong nghiên cứu tương ứng chiếm $70 \%$ và $75 \%$ tổng số trẻ 5 tuổi dân tộc Thái đang sinh sống tại huyện.

Tỷ lệ sâu răng theo tuổi: Theo WHO 2013 xếp loại tỷ lệ sâu răng: $<50 \% \rightarrow$ thấp; $50-70 \%$ $\rightarrow$ trung bình; $>70 \% \rightarrow$ cao. Như vậy tỷ lệ sâu răng ở trẻ 5 tuổi là $59,8 \%$ xếp vào mức độ sâu răng trung bình và tỷ lệ sâu răng của trẻ 12 tuổi là $14,3 \%$ xếp vào mức độ sâu răng thấp. Trong nghiên cứu này thãy tỷ lệ sâu răng sữa của trẻ 5 tuổi cao hơn nhiều so với tỷ lệ sâu răng vĩnh viễn ở trẻ 12 tuổi. Điều này cũng phù hợp với tình hình sâu răng chung là tỷ lệ sâu răng sữa cao hơn so với sâu răng vĩnh viễn.

Tỷ lệ sâu răng ở trẻ 5 tuổi: So sánh với tỷ lệ sâu răng của một số đề tài nghiên cứu khác cho thây tỷ lệ sâu răng của trẻ 5 tuổi ở đây cao hơn tỷ lệ sâu răng ở trẻ $5-6$ tuổi dân tộc Chepang, Nepal năm 2013 (52\%) [3] và thấp hơn so với tỷ lệ sâu răng ở trẻ 5 tuối tại thành phố Hồ Chí Minh (68 \%) [4]. Mỗi nghiên cứu được tiến hành ở mỗi thời điểm khác nhau, sự khác biệt về địa dư, thói quen ăn uống và phát triển kinh tế, xã hội ở mối địa phương nghiên cứu không giống nhau.

Tỷ lệ sâu răng ở trẻ 12 tuổi: So sánh với tỷ lệ sâu rắng của một số nghiên cứu khác cho thây tỷ lệ sâu răng của trẻ 12 tuổi thấp hơn tỷ lệ sâu răng ở trẻ 12 tuổi dân tộc Chepang, Nepal năm 2013 (41\%) [3]; nghiên cứu của Nguyễn Thi Cẩm Hồng ở Hồ Chí Minh là 44,7\%\% [4]; thấp hơn nhiều so với nghiên cứu của Nguyển Thị Thảo Trinh ở Lâm Đồng năm 2010 là 69,3\% [5]; nghiên cứu của Trần Thanh Tuấn ở Vînh Long năm 2012 là 53,2\% [6]. Lý giải cho tỷ lệ sâu răng ở cả hai lứa tuổi trong nghiên cứu này thấp có lẽ do trẻ dân tộc Thái ở địa phương đại đa số là con em gia đình nông thôn, cha me làm nông nghiệp, nương rẫy, điều kiện kinh tế eo hẹp, không có tiền để mua quà, bánh keo cho con cái ăn vặt. Việc sử dụng thức ăn sẵn, bánh kẹo, nước ngọt ít. Ở trẻ 5 tuổi tỷ lệ sâu răng có cao hơn nhưng chủ yếu tập trung ở một vài xã gần trung tâm huyện, có điều kiện được ăn, uống quà vặt hơn trẻ ở các xã khác. Một số yếu tố khác như chủng tộc hay dinh dưỡng có thể ảnh hưởng đến. Đặc biệt là tác động của fluor [7] có thể ảnh hưởng đến sâu răng.

Tỷ lệ sâu răng theo giới: Tỷ lệ sâu răng ở trẻ 5 tuổi trẻ nam cao hơn trẻ nữ một chút nhưng ở trẻ 12 tuổi tỷ lệ này đảo chiêu, trẻ nữ sâu răng cao hơn so với trẻ nam $(16,9 \%$ so với $11,6 \%)$. Điều này có thể lý giải ở lứa tuổi 5 không có sự khác biệt nhiều về chế độ ăn nhai, chăm sóc, vệ sinh rằng miệng. Nhưng đến lứa tuổi 12 có thể trẻ nữ hay ăn quà vặt hơn hoặc có thể có thói quen sử dụng răng vào những việc khác như ngậm kẹp tóc khi chải đầu hoặc dụng cụ đan lát.

Sâu mất trám răng và sâu mất trám mặt răng, nhu câu điêuu trị: Sâu-mất-trám răng và sâu-mất-trám mặt răng phản ánh mức độ trầm trọng của bệnh sâu răng trong cộng đồng. Chỉ số sâu thể hiện tình trạng sâu răng hiện tại trong khi đó chỉ số răng mất do sâu, răng trám thể hiện tình trạng sâu răng trong quá khứ. Trong nghiên cứu này SMT-R của trẻ 5 tuổi là $2,71 \pm 3,22$ xếp vào mức độ trung bình theo phân loại của WHO 2013, trong đó chủ yếu là chỉ số sâu, chỉ số mất hoàn toàn không có, chỉ số trám rất ít có thể do trẻ ít đi khám hay trám răng. So sánh với một vài nghiên cứu khác thây SMT-R của trẻ 5 tuổi cao hơn SMT-R của trẻ 5 tuổi dân tộc Chepang, Nepal năm $2013(1,59 \pm 0,31)$ [3], thấp hơn so với SMT-R của trẻ 5 tuổi thành phố Hồ Chí Minh năm $2004(3,52 \pm 3,82)$ [4]. Sâu mất trám mặt răng ở trẻ 5 tuổi trong nghiên cứu này khá cao $(8,36 \pm 11,5)$, có thể do việc dự phòng bệnh răng miệng và các chương trình chuyên biệt dự phòng bệnh răng miệng cho trẻ chưa tốt. SMT-R ở trẻ 12 tuổi trong nghiên cứu này là $0,21 \pm 0,56$ và $S M T-M R$ là $0,45 \pm 1,56$ ở mức độ rất thấp theo phân loại của WHO 2013. So sánh với một số công trình nghiên cứu khác thấy SMT-R của trẻ 12 tuổi trong nghiên cứu này thấp hơn so với SMT-R của trẻ 12 tuổi dân tộc Chepang, Nepal năm $2013(1,59 \pm 0,52)$ [3], và ở nghiên cứu khác của Nguyễn Thị Cẩm Hồng với người Hoa ở Hồ Chí Minh là 1,26\% [4]; của Nguyển Thị Thảo Trinh với người K'ho ở Lâm 
Đồng là 1,79\%[5]; nghiên cứu của Trần Thanh Tuấn với người Kinh ở Vĩnh Long là 1,24\% [6]. Lý giải cho SMT-R ở trẻ 12 tuổi trong nghiên cứu này thấp là do tỷ lệ sâu răng ở tuổi này thấp, thành phần trám rất ít, trong khi đó thành phần mất răng bằng 0 , có thể tình hình chăm sóc, điều trị bệnh sâu răng tại địa bàn còn nhiều hạn chế.

\section{KẾT LUÂN}

Tỷ lệ hiện mắc: Tỷ lệ sâu răng ở trẻ 5 tuổi là $59,8 \%$; xếp vào mức độ trung bình theo phân loại của WHO 2013; trẻ nam (62\%) cao hơn trẻ nữ $(57,2 \%)$ với sự khác biệt không có ý nghĩa thống kê $(p>0,05)$. Tỷ lệ sâu răng ở trẻ 12 tuổi là $14,3 \%$; xếp vào mức độ thấp; nam $(11,6 \%)$ thấp và nữ $(16,9 \%)$ nhưng không có ý nghĩa thống kê $(p>0,05)$.

Mức độ trâm trọng: ở nhóm trẻ 5 tuổi Sâumất-trám răng trung bình ở mức độ trung bình $(2,71 \pm 3,22)$, trong đó chủ yếu là chỉ số sâu, chỉ số mất hoàn toàn không có, chỉ số trám rất ít; Sâu-mất-trám mặt răng trung bình khá cao $(8,36 \pm 11,5)$. Ở nhóm trẻ 12 tuổi SMT-R trung bình là $0,21 \pm 0,56$ và SMT-MR trung bình là $0,45 \pm 1,56$, xếp vào mức độ rất thấp.

Nhu câu điêu trị: Có 0,52 răng/ 1 trẻ 5 tuổi và 0,13 răng/1 trẻ 12 tuổi cần trám 1 mặt răng. Có 0,79 răng/ 1 trẻ 5 tuổi và 0,04 răng/1 trẻ 12 tuổi cần trám 2 mặt răng.

TÀI LIẸU THAM KHẢO

1. Chính phủ (2011). Quyết định phê duyệt Chiến lược quốc gia bảo vệ, chăm sóc và nâng cao sức khỏe nhân dân giai đọan 2011-2020, tầm nhìn đến năm 2030. Quyết định số 122/QĐ-TTg của Thủ tướng Chính phủ.

2. World Health Organization (2013). Oral health surveys: Basis methods, 5th edition, France.

3. Dixit, Lonim et al. (2013). Dental caries prevalence, oral health knowledge and practice among indigenous Chepang school children of Nepal. BMC oral health. 13. 20. 10.1186/14726831-13-20.

4. Nguyê̂n Thị Cẩm Hông (2011). Kiến thức, hành vi và tình trạng sâu răng của học sinh lứa tuổi 12 và 15 tại Quận 5 , Thành phố Hồ Chí Minh năm 2010. Luận án chuyên khoa cấp 2, Đại học Y Dược thành phố Hồ Chí Minh.

5. Nguyễn Thi Thảo Trinh (2011). Tình trang bênh sâu răng, nha chu học sinh dân tộc K'ho và Kinh tuổi 12,15 tại tỉnh Lầm Đồng năm 2010. Luân án chuyên khoa cấp 2, Đại học Y Dược thành phố Hồ Chí Minh.

6. Trân Thanh Tuấn (2014). Nghiên cứu tình trạng sức khỏe răng miệng và các yếu tố liên quan của trẻ em 12 và 15 tuổi tai các trường trung hoc cơ sở thị xã Bình Minh, tỉnh Vĩnh Long năm 2013. Luận án chuyên khoa cấp 2, Đại học Y Dược Cần Thơ.

7. Riordan PJ. (1999). Fluoride supplements for young children: an analysis of the literature focusing on benefits and risks. Community Dent Oral Epidemiol;27(1):72-83.

\section{NGHIÊN CỨU ĐĂC ĐIỂM, KẾT QUẢ SƠ CỨU BAN ĐẦU VÀ ĐIỀU TRI THƯO'NG TÍCH DO TAI NẠN GIAO THÔNG ĐƯỜNG Bộ TẠI BỆNH VIỆN ĐA KHOA TRUNG TÂM AN GIANG NĂM 2020-2021}

\section{TÓM TẮT}

Đặt vấn đề: tai nạn giao thông trên thế giới và Việt Nam còn rất phổ biến, việc sơ cứu ban đâuu còn hạn chế. Muc tiêu: mô tả một số đặc điểm tai nạn giao thông đường bộ và đánh giá sơ cứu ban đâu, kết quả điều trị thương tích do tai nan giao thông đường bộ. Đối tượng và phương pháp: mô tả cắt ngang trên 420 bệnh nhân tai nạn giao thông đường bộ tại bệnh viện đa khoa trung tâm An Giang. Kết quả: tai nạn vào ban ngày là $57,4 \%$, ban đêm là $42,6 \%$. Phương tiện gây tai nạn phổ biến là mô tô $(81,7 \%)$;

*Bệnh viện Đa khoa trung tâm An Giang

**Trướng Đai hơc Y Dước Cần Tho

Chịu trách nhiệm chính: Nguyễn Trung Kiên

Email: ntkien@ctump.edu.vn

Ngày nhận bài: 2.11.2021

Ngày phản biên khoa học: 24.12.2021

Ngày duyệt băi: 4.01 .2022

\section{Nguyễn Minh Hải*, Nguyễn Trung Kiên**}

xảy ra tại thành thị $(63,3 \%)$ và nông thôn $(36,7 \%)$; Xét nghiềm có $25,2 \%$ bệnh nhân có cồn trong máu. Tỷ lệ chấn thương chi $(31,9 \%)$ và chân thương đâu mặt cổ $(30,7 \%)$. Mức độ năng các thương tích: nhe $(95,5 \%)$, trung bình $(3,1 \%)$, nặng $(1,4 \%)$. 36,9\% bênh nhân được sơ cứu tai hiên trường, kỹ thuật sơ cứu không tốt chiếm $69,0 \%$. Bệnh nhân được sớ cứu đúng cách $(17,4 \%)$, khống đúng cách $(82,6 \%)$. Đảm bảo an toàn khi vận chuyển là $51,0 \%$. Điều trị nội khoa chiếm tỷ lê cao nhất $(43,6 \%)$, phấu thuất cấp cứu (14,5\%). Kết quả điêu trị khỏi $89,3 \%$, tử vong $0,5 \%$. Đánh giá kết quả điều trị thành công $94,5 \%$, không thành công 5,5\%. Kết luận: việc sơ cứu ban đầu nan nhân tai nạn giao thông còn nhiều hạn chế.

Tư khóa: thương tích, tai nạn giao thông đường bộ, sơ cứu ban đầu.

\section{SUMMARY \\ STUDY OF CHARACTERISTICS, OUTCOMES OF FIRST-AID AND TREATMENT OF ROAD}

